\title{
A METACOGNITIVE MOOC FRAMEWORK
}

\author{
Jennifer Roberts, Ignatius Gous, University of South Africa, South Africa
}

\section{Abstract}

MOOC completion rates are well documented as being very low, in most cases, between 5\% to $15 \%$ (Greene, Oswald, \& Pomerantz, 2015; Jordan, 2014). Many reasons have been suggested for the low completion rate. This paper investigates the thesis that one of the predictors of the low completion rates, is that students are not satisfied with the overall experience (structure, content, delivery, etc.) of the MOOC. According to the SERVQUAL measurement scale of satisfaction, service quality can be defined as the difference between expectations and actual experiences. The argument put forward in this paper is that service quality will be enhanced if students' expectation of the MOOC is well understood and that they are properly prepared for what to expect when undertaking the MOOC. This paper follows from an already accepted research paper featuring an auto-ethnographic journey of undertaking a MOOC. The author proposed a metacognitive MOOC framework, from a learner's perspective, based on her MOOC journey. In this paper, this metacognitive MOOC framework is examined in terms of reflective as well as practical components, to assist prospective MOOC students to be prepared for the experience and enhance their satisfaction with their MOOC.

\section{Background and problem statement}

MOOCs have been heralded by some as the answer to providing adult education to support lifelong learning (Day, 2014). Others disagree and refer to "nightmare scenarios" if institutions move from traditional student-teacher interaction to the MOOC model (Day, 2014).

One of the major criticisms of MOOCs is the extremely low completion rate (Khalil \& Ebner, 2014; Balsh, 2013). Completion rates, particularly in xMOOCs, are acknowledged to be relatively low (Breslow, Pritchard, de Boer, Stump, Ho, \& Seaton, 2013). Onah, Sinclair, and Boyatt (2014) suggest many reasons for the low completion rate, with one of them being learner dissatisfaction with the MOOC. They state that many students do not have clear expectations of what the course is about or that their expectations are actually unrealistic.

The satisfaction of college students can be one of the main predictors of their academic success. Quality of service, unlike a product, cannot be easily measured. For example, quality of a product, say an automobile can be easily measured by different parameters like power, torque, fuel consumption, features, time to accelerate, time to brake, crash co-efficient etc. However, in service, the parameters are difficult to measure due to the inherent 
characteristics of service like intangibility, heterogeneity and inseparability (simultaneous production and consumption). Hence, service quality is more a measure of perception of customer satisfaction, and therefore difficult to have a standard construct. Parasuraman, Berry, and Zeithaml (1991) define service quality as the difference between consumer expectations and perceptions of service performance.

The contention in this paper is that service satisfaction is an intersection between expectation and actual experience. Therefore, the student's expectation of the MOOC will play a role in their overall satisfaction.

Roberts (2019) developed a Metacognitive MOOC Framework for prospective MOOC students (Annex 1). This framework is based on practical as well as metacognitive questions that should assist students to understand and assess their suitability for completing a MOOC. Once their expectations are understood, through the assistance of this framework, then their overall satisfaction level should improve.

This paper therefore takes as its point of departure, the notion that clear and accurate student expectations of undertaking a MOOC will lead to improved satisfaction of the course. The Metacognitive MOOC Framework as proposed by Roberts (2019), is investigated further and substantiated by references to literature on each aspect of the framework.

\section{Methodology}

The Metacognitive MOOC Framework article is currently accepted for publication and is based on a qualitative auto-ethnographical research project. It uses a narrative thematic analysis based on Braun and Clarke's (2006) 6 stage analysis. The framework is grounded on the themes that were identified in Roberts's (2019) research. In this paper, the themes (in the form of questions in the framework) are discussed using existing literature on each theme. This is accordance with Ellis (2004; p.198) who states that "the narrative then needs to be surrounded and framed by an analysis of existing literature that should concentrate on how the analysis ties in with or questions existing literature and the accepted theories to which they refer".

\section{Low completion rate of MOOCs}

One of the main criticisms of MOOC is their low completion rates. Parr (2013) discusses research that indicates that MOOC completion rates are below 7\%. Other authors suggest that completion rates lie somewhere between 5\% and 15\% (Greene, Oswald, \& Pomerantz, 2015; Jordan, 2014). Cognisance should be taken regarding the well-documented low completion rates of distance education students in general (Simpson, 2012). Many people seem eager to disregard MOOCs based on this low completion rate, but accept that it is common in many distance education courses

Conole (2015) discusses a 2-way dilemma in MOOCS. On the one hand MOOCs can be seen as the solution to education challenges in terms of accessibility, affordability and time. On the other hand, low completion rates suggest that MOOCs are not fulfilling this need. 
Khalil and Ebner (2013), concur that one of the major concerns regarding MOOCs is the completion rate of the courses. Balsh (2013) supports this. He asserts that the low completion rates are often misleading as MOOC students are more likely to enrol for a course that interest them. Because the MOOCs are very often free of charge, these students are more likely to withdraw before completion.

Onah, Sinclair, and Boyatt (2014) list several reasons that could influence the low completion rate of MOOCs. They state that little research has been carried on the effect size of each of these factors. One of the reasons for high dropout as suggested by Onah et al. (2014) is that many students do not have clear expectations of what the course is about, or that their expectations are unrealistic. They list the following as reasons for the high dropout rate of MOOC students: lack of time; no real intention to complete; course difficulty, starting late; bad previous experience; lack of digital skills and incorrect expectations. Figure 1 shows these reasons, and highlights the possibility that a better understanding of the MOOC process will lead to more realistic expectations and hence a higher level of satisfaction. This is in line with Parasuraman et al.'s (1991) theory that satisfaction is dependent on expected versus actual experience of completing a MOOC. Thesis is therefore that dropout rate will improve if satisfaction of the course is increased.

According to Howarth, D’Alessandro, Johnson, and White (2016), MOOC students are more likely to continue their studies at university if their MOOC experience is satisfying, and that progress in the MOOC is dependent on their goal alignment being maintained. Therefore, it is important to create the correct expectation for prospective students before starting the MOOC. This will reduce the gap between the expected and actual experience of MOOC students. A more realistic expectation should narrow the gap between the expectation and the actual experience and lead to an overall improvement in satisfaction. 
A Metacognitive MOOC Framework

Jennifer Roberts, Ignatius Gous

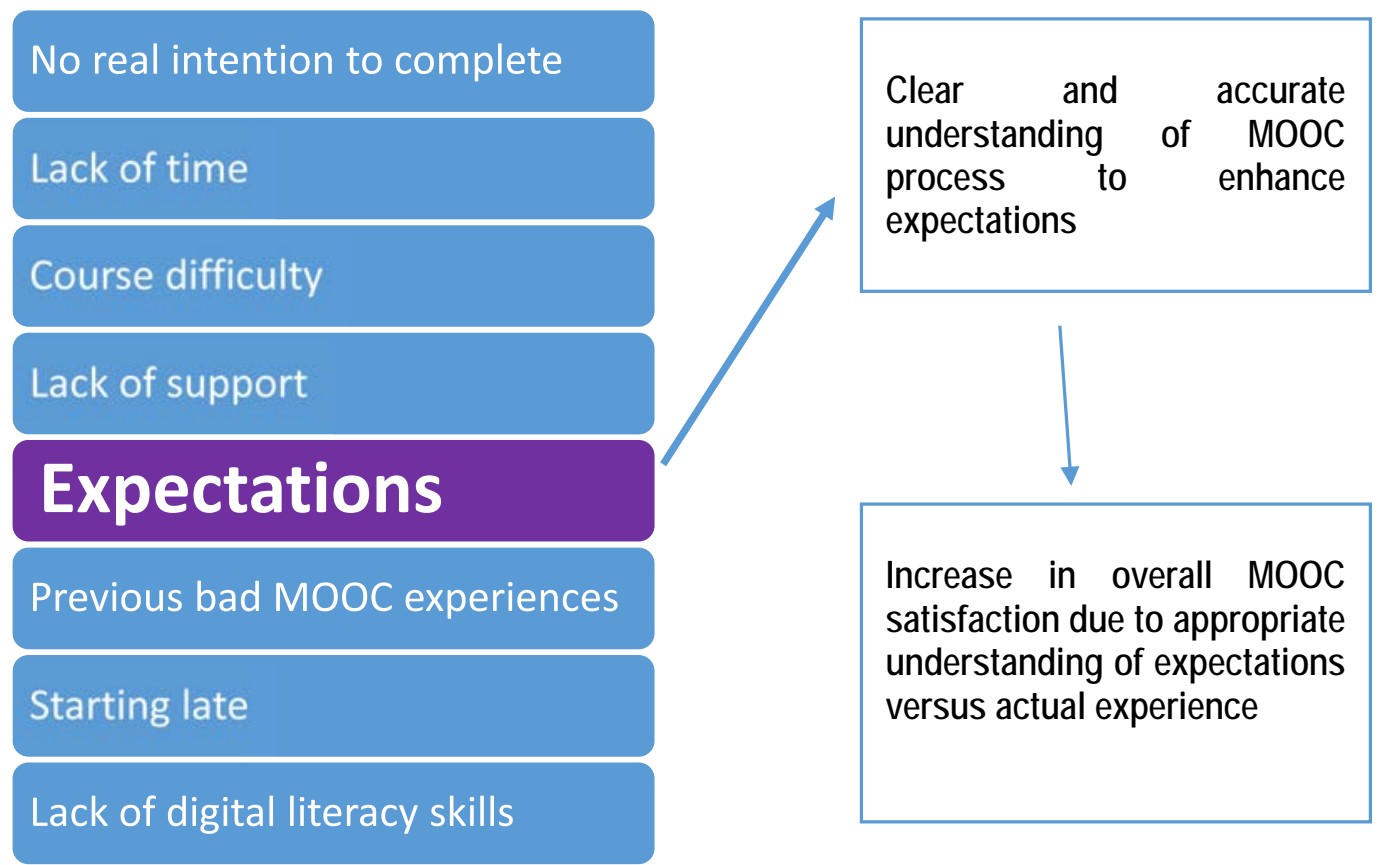

Figure 1. Conceptual framework for increased student satisfaction with MOOCs Based on Onah et al.'s (2014) reasons for low completion rate of MOOCs

According to Parasuraman et al. (1991), satisfaction is dependent on expected versus actual experience, and therefore, satisfaction levels of MOOCs can be increased by a clear and accurate understanding of the MOOC expectations. One way of doing so is to use the Metacognitive MOOC Framework (Roberts, 2019) that is based on both reflective as well as practical questions.

\section{Flavell's theory of metacognition and reflection}

According to Flavell (1976; p.232), "metacognition refers to one's knowledge concerning one's own cognitive processes or anything related to them". Flavell (1979) divides metacognitive knowledge into four categories: knowledge of self, goals, tasks and strategies. In the framework proposed by Roberts (2019) each question is framed around one of these four variables.

Self-reflection has been identified as an important aspect of general learner development in recent years (Park, 2003; Belobrovy, 2018). Self-reflection can play a significant role for learner's taking responsibility for their studies, their own empowerment and motivation. Davis, Herbst, and Busick (2013), state that the process of self-reflection can contribute to the students understanding their own learning process. Metacognition can therefore be a type of reflection - thinking about your own thinking - with the result of enhancing the learning experience.

Roberts (2019) proposed a metacognitive MOOC Framework based on her auto ethnographical research journey on completing a MOOC. The framework is based on the analysis of her reflections and journal entries as a learner participating in her first MOOC. This framework should assist first time MOOCers with understanding their own human 
factors that could possibly influence their satisfaction with the MOOC journey. The framework can be used by both the MOOC providers, as well as the learners themselves.

The framework is divided into practical and metacognitive questions that any prospective MOOCer should understand.
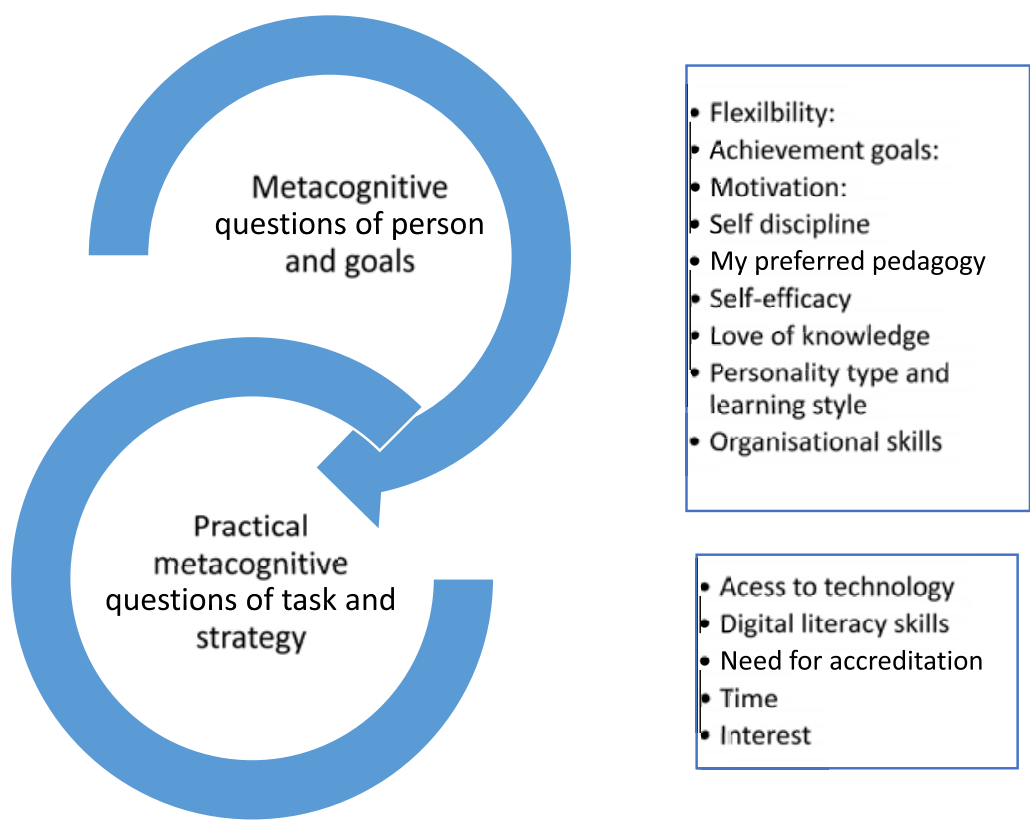

- Acess to technology

- Digital literacy skills

- Need for accreditation

- Time

- Interest

Figure 2. The Metacognitive MOOC Framework (Roberts, 2019)

\section{Unpacking the framework}

The research that lead to this framework is currently in print in "Distance Education in China, Vol. 11". The aim of this paper is to unpack the different elements of the framework, relate them to Flavell's (1979) variables of metacognitive knowledge and connect their validity to previously published research on each of the elements of the framework. The reason for this is that the potential MOOCer can create a realistic expectation around the MOOC, to enhance satisfaction. The framework makes a distinction between practical questions that could influence MOOC satisfaction and metacognitive reflective questions, which together will prepare the student for a better MOOC experience.

Flavell (1979) refers to metacognitive knowledge in terms of the four variables, i.e. knowledge of self, goals, task and strategy. Figure 1 is hence unpacked in terms of these four variables, although there is a large degree of overlapping between the four variables. Metacognitive knowledge of person includes all knowledge of yourself, your beliefs, your preferred learning style and your understanding of others. Knowledge of task encompasses the ability to understand that some tasks are more difficult than others are. Knowledge of strategies also plays an important role in understanding which strategies will be most effective in carrying out the task. 
Desautel (2009; p.1) sums this up by stating that metacognitions can be described as a complex process of thinking that can result in a person obtaining a "nuanced" understanding of themselves.

\title{
Metacognitive knowledge of person
}

This category includes the following aspects of the framework - personality, learning type (self-pedagogy), flexibility, organisational skills, self-efficacy and self-discipline.

\section{Understanding your personality type}

Bocchi, Eastman, and Owens-Swift (2004) suggest that many potential MOOC students do not take into consideration their own personality style, but rather focus on the practical considerations of convenience, availability and flexibility of the course. This is supported by Sheard and Lynch (2003) who highlight that one of the problems of web-based learning is that it that seldom considers the differing personality and learning styles of the students.

It is therefore important to understand your strengths and limitations based of your own personality type. Many different personality assessments are available such as the Myers Briggs (MBTI) and the OCEAN (or Big 5). The MBTI, which was developed in the 1960's by Katherine Cook Briggs and Isobel Myers, is based on the personality theories of Gustav Jung (Briggs \& Myers, 1980). Another well researched personality test is the OCEAN that describes five broad personality traits: openness to experience, conscientiousness, extraversion, agreeableness and neuroticism (McAdams, 2008).

The question asked in the framework is the following:

\begin{abstract}
"Have I ever undertaken a reliable personality type assessment test that frames my strong points as well as draws attention to areas that are more challenging for me? Do I really know and understand my own unique personality?"
\end{abstract}

\section{Learning type (self-pedagogy)}

Roberts (2019) found that MOOC pedagogy was able to provide her with basic content knowledge but did not necessarily go deep enough to ensure the development of critical thinking, reasoning and argumentative skills. MOOCs are often criticised for their "behaviourist" approach to learning (Kesim \& Altinpulluk, 2016; McGuire, Raaper, \& Niklova, 2016). However, in a report of learner's experiences of undertaking a MOOC at the University of Southampton, Wintrup, Wakefield, Morris, and Davis (2015) indicated that many MOOC students preferred the linear structure of the MOOC for providing basic content knowledge. Daniel (2012) states that xMOOCs are based on a behavioural epistemology and Amo (2013) postulates that cMoocs - those that focus on a connectivist learning approach

The following question from the framework regarding the type of learning the student requires should therefore be asked: 
"Do I prefer to learn in a linear behaviourist manner to obtain information and knowledge or would I rather adopt a more social constructivist approach that involves discussion and interactions with other students/course leaders etc.?"

\section{Flexibility}

There are different levels of flexibility for different MOOCs. Some MOOCs have strict start and end dates and deadlines for assignments, quizzes and exams. They work on an inflexible schedule and if the student misses a deadline, they do not receive credit for that part of the course. Other MOOCs are more flexible. Many of them have no fixed start date and the student can start whenever they want to and submit assignments in their own time.

Loya, Gopal, Shukla, Jermann, and Tormey (2015) studied the impact of conscientious behaviour on the completion rate of MOOCs. They found that the flexible nature of some MOOCs is better suited to students who possess high levels of planning, self-discipline and organisational skills. For this reason, a metacognitive understanding of your own levels of these skills is necessary. This is supported by Fasihuddan, Skinner, and Athauda (2013) who suggest that although some students like to learn at their own pace, deadlines from MOOCs could then prove to be challenging. Roberts (2019) found from her research that although she prefers flexibility and less structure, this led to her not completing (or even starting) the MOOC that had open-ended start and end dates. She needed the discipline of a structured MOOC to ensure that she completed it.

Here, it is important to reflect on your own preferred type:

"Do I prefer structured courses or those with a flexible deadline? Am I the kind of person who needs deadlines I order to complete a task or do I prefer an environment that I can adjust to my busy schedule?"

\section{Organisational skills}

There are many different formats to MOOCs. Some have strict start and end dates, as well as weekly deadlines and final exams. If the student fails to meet any of the deadlines, then they run the risk of failing the MOOC. Other MOOCs are open-ended - the student can decide when to start the MOOC and move at their own pace. As Roberts (2019) found, unless the student is well organised and able to plan appropriately, there is a danger that a self-paced MOOC will not be completed.

An understanding of your own organisational skills is therefore necessary. This ties in with the time management knowledge which is discussed later in the "Time management" subsection of "Metacognitive knowledge of strategy" section.

"How organised and methodical am I really? Do I have a good track record of sticking to a schedule?” 


\title{
Self-discipline
}

Following through on a MOOC requires a relatively high level of self-discipline, in addition to intrinsic motivation, which is discussed in paragraphs of the "Intrinsic motivation" subsection below.

Gillen (2013) discusses four important lessons that he learned from undertaking a MOOC. His lesson two states that for students taking a MOOC, self-motivation and self-discipline are even more important.

\begin{abstract}
"One advantage of in-person courses is the expectation that students will show up at certain times. Indeed, during my MOOC experience I felt none of the nagging guilt about skipping class that I experienced in my college years. My ability to work on the course at any time made it easy to put it off. In fact, I'm still working on the last few weeks of course material even though the course is already over. This procrastination wasn't about a lack of time - for instance, I am completely up to date on the TV show The Walking Dead - but rather a lack of self-discipline." (Gillen, 2013)
\end{abstract}

This is in line with the experience of Roberts (2019) who found that lack of self-discipline resulted in her not even starting the open ended and flexible MOOC.

"Am I impulsive or rational? Do I let my feelings overwhelm me at times? Do I need instant gratification or am I able to see the bigger picture and make sacrifices now to achieve my long-term goal?”

\section{Self-efficacy}

Self-efficacy can be defined as "belief in one's capabilities to organize and execute the courses of action required to produce given attainments" (Bandura, 1997; p.3). It means believing in yourself and that your own efforts are strong enough to see you through a difficult time. A person's sense of self-efficacy is enhanced when they have a strong sense of responsibility for their own situation as well as being able to make decisions about their own circumstances.

Tsai, Chuang, Liang, and Tsai $(2011 ;$ p.22) recently concluded from a review of the literature regarding self-efficacy in internet-based learning environments that "student's self-efficacy plays a positive role in their attitude towards and their processes and outcomes derived from Internet-based learning".

"How confident am I that I will be able to master this course? Do I feel that I have the ability to pass even if the subject is out of my comfort area? Do I believe in my own abilities even if it means that I will have to put in a lot of time and effort?" 


\section{Metacognitive knowledge of goals}

Metacognitive knowledge of goals (Flavell's second variable) includes aspects such as motivation, and interest, MOOC achievement goal and the need for accreditation.

\section{Intrinsic motivation}

Pintrich (2003) puts forward five different motivational constructs being: interest, achievement goals, value beliefs, self-efficacy and control beliefs. The Metacognitive MOOC Framework (Roberts, 2019) highlights three of these motivational constructs - interest (including love of knowledge), achievement goals and self-efficacy. Interest is discussed in the "Interest" subsection of the "Metacognitive knowledge of task" section below and self-efficacy has been addressed in "Self-efficacy" above.

Intrinsic as well as extrinsic motivational factors need to be considered when deciding to undertake a MOOC. Within the parameter of knowledge of person, intrinsic motivation, which is derived from intangible factors, plays an important role. An example of intrinsic motivation would be when you do something because you want to and find it interesting e.g. dancing or listening to music. You do it because you enjoy it! When you are intrinsically motivated, your behaviour is motivated by your internal desire to carry out the task. Extrinsic motivation, on the other hand, occurs when there is a contributory reason for that behaviour e.g. going for a run, to increase your heart rate for health purposes. This differs from intrinsic motivation where the love of running is the motivational factor.

The potential MOOC student needs to determine their motivation for undertaking the MOOC under consideration. Is it for a thirst for additional knowledge on the subject or a necessity in order to "prove" knowledge for a work promotion etc.? Yama (2017) states that intrinsic motivation is essential for decreasing dropout rates in online learning contexts. Espinosa, Sepúlveda, and Montoya (2015), who found that a lack of learner intrinsic motivation is one of the main reasons for the high dropout rates in MOOCs, support this. Where a MOOC does not offer accreditation and certification, and the main aim is to provide increased knowledge, intrinsic motivation is a prerequisite.

Here, the questions that need to be asked are as follows:

"Am I registering for this MOOC to expand and/or supplement my current knowledge on this subject even through it does not necessarily relate directly to my current career? What is my reason for registering for this course?"

\section{Achievement goal}

There are many different reasons for students registering for a MOOC. It is important for the student to fully understand their motivation and reason for undertaking the MOOC and the outcome that they wish to achieve. Some students might wish to participate, with the intention of completing the course, staying the distance, and gaining the full experience of the MOOC. This will be acknowledged through accreditation for completing and passing the 
MOOC - through certification, badging or some other form of recognition. Alternatively, the MOOC might be used to simply "fill in" missing content knowledge and thus completion and accreditation are not that important. Other reasons could include: broadening your horizons, professional development, learning a new skill and getting a taste of university teaching. A study by Liu, Kang, and McKelroy (2015), revealed that the majority of MOOC students were professional people who were looking for opportunities to advance their careers without the constraints of time and place.

"The question for the construct of achievement goal is thus: What is the result that I want to achieve by taking this MOOC? Do I want to complete the whole course and receive certification for my knowledge and efforts or is it more important to me to only find additional knowledge in the areas that interest me?"

\section{Metacognitive knowledge of task}

The task at hand is the actual MOOC that the student wishes to register for. The student needs to understand the scope of the MOOC, including the content that will be covered. An interest in the topic is a prerequisite as well as aspects such as having a love of knowledge and a desire to learn - all indication of a lifelong learner.

\section{Interest}

Ryan and Deci (2000) state that "if a person is simply not interested in a particular learning activity, he will not be intrinsically motivated for engagement". This ties in too with understanding the real reason why the student wants to register for a MOOC. Anderson (2013) suggests that many students are motivated by an initial curiosity in the MOOC content, but their intention is never to complete the MOOC. They might only be interested in certain parts of the MOOC content.

"What about this MOOC has sparked my interest? Is it a subject that I am particularly interested in?"

\section{Love of learning}

This theme ties in with achievement goals stated in "Achievement goal" subsection above. It is important for the potential MOOC student to understand the exact reason for undertaking the MOOC. The questions being asked here relates to the reason for registering for a MOOC. If the learner is fully aware of this reason, whether it be for the love of acquiring new knowledge or a necessary way to obtain information and content for a purpose. The potential MOOCer needs to possess a love of learning and an understanding of their achievement goal and then search for MOOCs that relate to their own interests and passions - this could range from building robots to Shakespearean literature and all things in between.

"Am I registering for this MOOC to expand and/or supplement my current knowledge on this subject even though it does not relate directly to my current 
studies/career? Am I a lifelong learner who is motivated by a thirst for new knowledge?"

\section{Metacognitive knowledge of strategy}

Strategies refers to the tools that are needed and that the student possesses to complete a fully online MOOC.

\section{Time management}

Many students seem to underestimate the time needed to successfully complete a MOOC. They see the time guidelines as only a vague indication of how much time is needed. It is therefore imperative that each student thinks conscientiously about the time that they have available and fully understands the time commitment that is necessary. When a student is caught up in the hype of undertaking a MOOC, in their excitement, it is often tempting to register for multiple courses, not fully understanding the time commitment that is required. Many MOOCs provide a fixed and inflexible format in terms of timing (Onah et al., 2014). Smith, Murphy, and Mahoney (2003) state that online readiness for students focuses on time management as well as self-directedness, motivation, learning styles and experiences. These skills are just as necessary in the MOOC era. Students who lack study skills and good work habits run the risk of dropping out of MOOCs (Gutierrez-Rojas, Alario-Hoyos, PerezSanagustin, Leony, \& Delgado-Kloos, 2014). Effective time management is seen as a critical study skill.

"How much time do I have available to spend on this course? Does it realistically equate to the time suggested by the course provider? Do I have the time to do more than one MOOC or should I rather spread them over a longer timespan?"

\section{Access to technology}

Van Dyk and Hacker (2003) classified four types of access to online learning and their barriers: mental access, material access, skills access and usage access.

Prospective MOOC students need to understand that the MOOC is a fully online course and can only be completed if they have access to technology that supports it. Many MOOCs make use of video podcasts, interactive sessions and other continuously evolving technologies. Their hardware must support the instructional design techniques. Anecdotal evidence from observations at the author's own institution show that many students tick the box to say that they understand that the course they are taking is fully online - but afterwards complain that they do not have a laptop or internet connectivity. This problem is prevalent in many developing countries where there is a lack of reliable broadband connectivity, compounded by high costs. Roberts (2019) found that although she had access to a high-quality device, and Wi-Fi connectivity at both work and home, there were times that she experienced levels of frustration because of interruptions in both her connectivity and hardware problems. These challenges may lead to feelings of annoyance and exasperation, which could result in dropout. 
It is therefore important to assess your own technology and internet access to be certain that you have the required specifications.

"Do I have access to the required technology for this MOOC? Is my internet access easily available and consistent? Do I have internet at home and/or work or do I have to rely on internet hotspots?"

\section{Digital literacy skills}

Many authors have attempted to define digital literacy (Ilomäki, Pavola, Lakkala, \& Kantosalo, 2016; Pokpas, 2014; Stordy, 2015). Julien (2015) defines digital literacy as "The set of skills, knowledge and attitudes required to access digital information effectively, efficiently, and ethically".

Drawing once again on van Dyk and Hacker's (2003) classification, one of the barriers to online learning, and by deduction to MOOCs as well, is the necessary levels of digital literacy skills that are required. This is particularly widespread in developing countries where poor infrastructure at school level sometimes results in low levels of digital literacy.

An honest appraisal and assessment of the individual's digital literacy skills is therefore an important aspect of preparing to undergo a MOOC. The question related to this that needs to be asked is:

"How would I rate my computer skills? Can I download files, carry out internet searches, and interact with social media?"

\section{Conclusion}

The aim of this paper was to discuss the Metacognitive MOOC Framework proposed by Roberts (2019). The framework was developed to assist would-be MOOC students to better prepare themselves for the MOOC experience. The contention is that if students are well prepared and have realistic expectations, their level of satisfaction will improve. This could, in turn, lead to a higher completion rate of MOOCs.

The framework is based on Flavell's (1979) metacognitive principles of thinking about various aspects related to undertaking a MOOC i.e. thoughts about self, motivation and goals, the actual task and the strategy needed to complete the task. An understanding firstly of oneself your own personality, and the related aspects of self-discipline and self-efficacy, organisational as well as self-pedagogical understanding, sets the basis for this metacognitive framework. Once the learner has thought about these aspects, then motivation and achievement goals need to be assessed. The framework places an emphasis on understanding your own motivation and the results that you wish to achieve through undertaking a MOOC - whether it be for lifelong learning aspects, an interest in a hobby, professional development or filling a knowledge gap. The framework then homes in to the actual task - in this case the MOOC, and prepares the student to think about the MOOC that they are intending to register for, to understand the content, the structure and the instructional design. Finally, the 
learner needs to comprehend the types of strategies that they are going to use to achieve their desired outcomes. These are practical questions related to time management, access to technology and digital literacy skills.

All the above are necessary is to avoid a sense of disappointment when the outcomes are not what you expected.

\section{References}

Amo, D. (2013). MOOCs: Experimental approaches for quality in pedagogical and design fundamentals. Paper presented at the TEEM '13, November 14 - 15 2013, Salamanca, Spain.

Balsh, T. (2013, July 24). Why the "Low MOOC Completion Rate". Statistic is a Bogus Argument. The augmented trader [Blog post]. Retrieved March 13, 2019, from http://augmentedtrader.wordpress.com/2013/07/24/why-the-low-mooc-completion-ratestatistic-is-a-bogus-argument

Belobrovy, A. (2018). Theories on Self-Reflection in Education. Paper presented at Conference: IAFOR ACE.

Bocchi, J., Eastman, J., \& Owens-Swift, C. 2004. Retaining the online learner: Profile of students in an online MBA program and implications for teaching them. Journal of Education for Business, March/April, 245-253. http://dx.doi.org/10.3200\%2FJOEB.79.4.245-253

Braun, V., \& Clarke, V. (2006). Using thematic analysis in psychology. Qualitative Research in Psychology, 3(2), 77-101.

Breslow, L., Pritchard, D., de Boer, J., Stump, G., Ho, A., \& Seaton, D. (2013). Studying learning in the worldwide classroom: Research into edX's first MOOC. Research \& Practice in Assessment, 8, 13-25.

Briggs, I. \& Myers, P. (1980). Gifts differing. Palo Alto: CA.

Conole, C. (2015). Designing Effective MOOCs. Educational Media International, 52, 239-25.

Daniel, J. (2012). Making sense of MOOCs: Musings in a maze of myth, paradox and possibility. Journal of Interactive Media in Education, 3. Retrieved December 4, 2018, from https://jime.open.ac.uk/articles/10.5334/2012-18/

Davies, A., Herbst, S., \& Busick, K. (2013). Quality assessment in high schools: Accounts from teachers. Courtney, BC: Connections Publishing.

Day, D. (2014, April 10). 'MOOC World': Experts clash over differing visions of education technology. Princeton University News. Retrieved May 12, 2018 from https://www.princeton.edu/news/2014/04/10/mooc-world-experts-clash-over-differingvisions-education-technology?section=topstories

Desautel, D. (2009). Becoming a thinking thinker: metacognition, self-reflection, and classroom practice. Teachers College Record, 111(8), 1997-2020. 
van Dijk, J., \& Hacker, K. (2003). The digital divide as a complex and dynamic phenomenon. Information society, 19(4), 315-326.

Ellis, C. (2004). The ethnographic I: a methodological novel about autoethnography. Walnut Creek: AltaMira Press.

Espinosa, B., Sepúlveda, G., \& Montoya, M. (2015). Self-motivation challenges for students involvement in the Open Educational Movement with MOOC. Revista de Universidady Sociedad del Conocimiento, 12(1), 91-103.

Fasihuddin, H., Skinner, G., \& Athauda, R. (2013). Boosting the opportunities of Open Learning (MOOCS) through learning theories. GSTF Journal on Computing, 3(3). Retrieved December 2, 2018, from https://www.globalsciencejournals.com/content/pdf/10.7603\%2Fs40601-013-0031-z.pdf

Flavell, J. (1976). Metacognitive aspects of problem solving. In L. Resnick (Ed.), The nature of intelligence (pp 231-236). Hillsdale, NJ: Erlbaum.

Flavell, J. (1979). Metacognition and cognitive monitoring: a new area of cognitivedevelopmental inquiry. American Psychologist, 34(10), 906-911.

Gillen, A. (2013, April 4). The four lessons I learned by taking a MOOC. American Institutes for Research [Blog post]. Retrieved February 3, 2019, from https://www.air.org/edsectorarchives/publications/four-lessons-i-learned-taking-mooc

Greene, J., Oswald, C., \& Pomerantz, J. (2015). Predictors of retention and achievement in a massive open online course. American Educational Research Journal, 52(5), 925-955. doi: $10.3102 / 0002831215584621$

Gutiérrez-Rojas, I., Alario-Hoyos, C., Pérez-Sanagustín, M., Leony, D., \& Delgado-Kloos, C. (2014). Scaffolding Self-learning in MOOCs. Paper presented et the European MOOCs Stakeholder Summit, 2014.

Howarth, J., D’Alessandro, S., Johnson, L., \& White, L. (2016). Learner motivation for MOOC registration and the role of MOOCs as a university 'taster'. International Journal of Lifelong Education, 35(1), 74-85. doi: 10.1080/02601370.2015.1122667

Ilomäki, L., Paavola, S., Lakkala, M., \& Kantosalo, A. (2016). Digital Competence - an emergent boundary concept for policy and education research. Education in Technology, 21, 655-679.

Jordan, K. (2014). Initial trends in enrolment and completion of massive open online courses. The International Review of Research in Open and Distributed Learning, 15(1), 133-160. Retrieved March 21, 2019, from http://www.irrodl.org/index.php/irrodl/article/view/1651/281

Julien, H. (2015). Digital Literacy. Retrieved March 22, 2019, from https://www.igiglobal.com/chapter/digital-literacy/112623

Kesim, M., \& Altinpulluk, H. (2015). A theoretical analysis of MOOC types from a perspective of learning theories. Procedia - Social and Behavioural Sciences, 186, 15-19. 
Khalil, H., \& Ebner, M. (2014). MOOCs Completion Rates and Possible Methods to Improve Retention - A Literature Review. Paper presented at the World Conference on Educational Multimedia, Hypermedia and Telecommunications 2014 (ED-Media).

Liu, M., Kang, J. \& McKelroy, E. (2015). Examining learners' perspective of taking a MOOC: reasons, excitement, and perception of usefulness. Educational Media International, 52(2), 129-146. doi: 10.1080/09523987.2015.1053289

Loya, A. Gopal, A. Shukla, I., Jermann, P., \& Tormey, R. (2015). Conscientious Behaviour, Flexibility and Learning in Massive Open On-Line Courses. Procedia - Social and Behavioural Sciences, 191. doi: 10.1016/j.sbspro.2015.04.686

McAdams, D. (2008). The person: an introduction to the science of personality psychology $\left(5^{\text {th }}\right.$ ed.). New Jersey: Wiley.

McGuire, W., Raaper, R., \& Nikolova, V. (2106). Three perspectives on hybridizing x and c MOOCs to create an online course. International Multidisciplinary Journal, 3(2), 20-33.

Onah, D., Sinclair, J, \& Boyatt, R. (2014). Dropout rates of massive open online courses: behavioural patterns. EDULEARN14 Proceedings, 5825-5834.

Parasuraman, A., Berry, L., \& Zeithaml, V. (1991). Perceived service quality as a customerbased performance measure: An empirical examination of organizational barriers using an extended service quality model. Human Resource Management, 30(3), 335-364. https://doi.org/10.1002/hrm.3930300304

Park, C. (2003). Engaging students in the learning process: The learning journal. Journal of Geography in Higher Education, 27(2), 183-199.

Parr, G. (2013). MOOC completion rates below 7\%. Retrieved March 22, 2019, from https://www.timeshighereducation.com/news/mooc-completion-rates-below7/2003710.article

Pintrich, P. (2003). A motivational science perspective on the role of student motivation in learning and teaching contexts. Journal of educational psychology, 95(4), 667-686.

Pollack Ichou, R. (2018). Can MOOCs Reduce global inequality in education? Australasian Marketing Journal, 26(2) 116-120. https://doi.org/10.1016/j.ausmj.2018.05.007

Pokpas, C. (2014). Towards a framework for the development of e-skills for digital inclusion in the Western Cape. Retrieved March 12, 2019, from https://etd.uwc.ac.za/xmlui/bitstream/handle/11394/4216/pokpas_c_msc_ems_2014_1.pd $\mathrm{f}$

Roberts, J. (2019) (in print). My MOOC journey: an auto-ethnographical account into lifelong learning. (Junhong Xiao trans.) Distance Education in China, 11.

Rosen, G. (2014). 'MOOC World': Experts clash over differing visions of education technology. Retrieved May 12, 2017, from http://www.princeton.edu/main/news/archive/S39/71/57E81/index.xml?section=topstorie S 
Ryan, R., \& Deci, E. (2000). Self-determination theory and the facilitation of intrinsic motivation, social development, and well-being. American Psychologist, 55(1), 68-78.

Simpson, O. (2013). Student retention in distance education: are we failing our students? Open Learning, 28(2), 105-119. doi: 10.1080/02680513.2013.847363

Smith, P., Murphy, K., \& Mahoney, S. (2003). Identifying factors underlying readiness for online learning: An exploratory study. Distance Education, 24, 57-68.

Stordy, P. (2015). Taxonomy of literacies. Journal of Documentation, 71(3), 456-476.

Tsai, C., Chuang, S., Liang, J., \& Tsai, M. 2011. Self-efficacy in Internet-based Learning Environments: A Literature Review. Educational Technology \& Society, 14(4), 222-240.

Wintrup, J., Wakefield, K., Morris, D., \& Davis, H. (2015). Liberating learning: experiences of MOOCs. Higher Education Academy. Retrieved November 6, 2018, from https://heacademy.ac.uk/sites/default/files/resources/liberating learning.pdf

Yama, P. (2017). Learner intrinsic motivation in online social learning platforms: a case study of massive open online course (MOOC) in Thailand. Retrieved March 3, 2019, from https://eprints.qut.edu.au/108005/5/Pittaya_Yamo_Thesis.pdf

\section{Annex 1. Metacognitive MOOC Framework (Roberts, 2019)}

\begin{tabular}{ll}
\hline Construct & Questions \\
\hline Flexibility & Do I prefer structured courses or those with a flexible deadline? Am I the kind \\
& of person who needs deadlines to complete a task or do I prefer an \\
& environment that I can adjust to my busy schedule? \\
Time & How much time do I have available to spend on this course? Does it \\
& realistically equate to the time suggested by the course provider? Do I have \\
& the time to do more than one MOOC or should I rather spread them over a \\
& longer timespan? \\
Organisational & How organised and methodical am I really? Do I have a good track record of \\
skills & sticking to a schedule? \\
Self-discipline & Am I impulsive or rational? Do I let my feeling overwhelm me at times? Do I \\
& need instant gratification or am I able to see the bigger picture and make \\
Access to & sacrifices now to achieve my long-term goal? \\
technology & Do I have access to the required technological devices that are required for \\
& this MOOC? Is my internet access easily available and consistent? Do I have \\
Digital literacy & internet at home and/or work or do I have to rely on Wi-Fi hotspots? \\
skills & How would I rate my computer skills? Can I download files, carry out internet \\
My type of & searches, and interact with social media? \\
learning & Do I prefer to learn in a linear behaviourist manner to obtain information and \\
& knowledge or would I rather adopt a more social constructivist approach that \\
involves discussion and interactions with other students/course leaders etc.? & Am I registering for this MOOC to expand and/or supplement my current \\
kove of & knowledge on this subject even though it does not relate directly to my \\
knowledge & current studies/career? \\
Motivation & Why am I thinking of registering for this Mooc? \\
Interest & What about this MOOC has sparked my interest? Is it a subject that I am \\
& particularly interest in?
\end{tabular}


Self-efficacy How confident am I that I will be able to master this course? Do I feel that I can pass even if the subject is out of my comfort area? Do I believe in my own abilities even if it means that I will have to put in a lot of time and effort?

Achievement What is the result that I want to achieve by taking this MOOC? Do I want to goals complete the whole course and receive certification for my knowledge and efforts or is it more important to me to only find additional knowledge in the areas that interest me?

Personality and Have I ever undertaken a reliable personality type assessment test that frames learning style my strong points as well as draws attention to areas that are more challenging for me? Do I really know and understand my own unique personality?

Reflexive thinking Do I spend time thinking deeply about my motivations, goals and plans for the future? Do I reflect on experiences and try to learn from them to avoid recurring problems?

Need for $\quad$ For this $\mathrm{MOOC}$, do I really need accreditation for job advancement, to put on accreditation my CV or to gain access to further studies? Alternatively, is it more important to me that I gain new knowledge as part of my lifelong learning journey? 